\title{
TJES
}

ISSN: 1813-162X

Tikrit Journal of Engineering Sciences

available online at: http://www.tj-es.com

\section{Determination of Flow through Homogeneous Earth Dams with Triangular Toe Filter}

\author{
Jawdat K. Abbas* \\ Civil Engineering Department, Tikrit University, Salahaldeen, Iraq. \\ E-mail : dr.jawdatkhadim@tu.edu.iq
}

(Received 29 November 2016, Accepted 16 January 2017, Available online 31 March 2017)

\begin{abstract}
Finite element method with a computer program SEEP/W were utilized to determine the quantity of flow through homogeneous earth dams with triangular toe filter. The effect of angle of upstream slope, angle of downstream slope, angle of toe filter, height of dam, crest width of dam, free board, length of toe filter and coefficient of permeability on the quantity of seepage were studied. The results show that, the seepage quantity decreased with increasing angle of toe filter, free board height and crest width of dam. Also, from the results can be concluded that, the flow quantity increased with increasing angle of upstream slope, angle of downstream slope and length of toe filter. Using statistical analysis by a SPSS-19 program, a new empirical equation was suggested to estimate the quantity of seepage through earth dams with triangular toe filter.
\end{abstract}

Keywords: Finite element, homogeneous earth dam, seepage quantity, SEEP/W, toe filter.

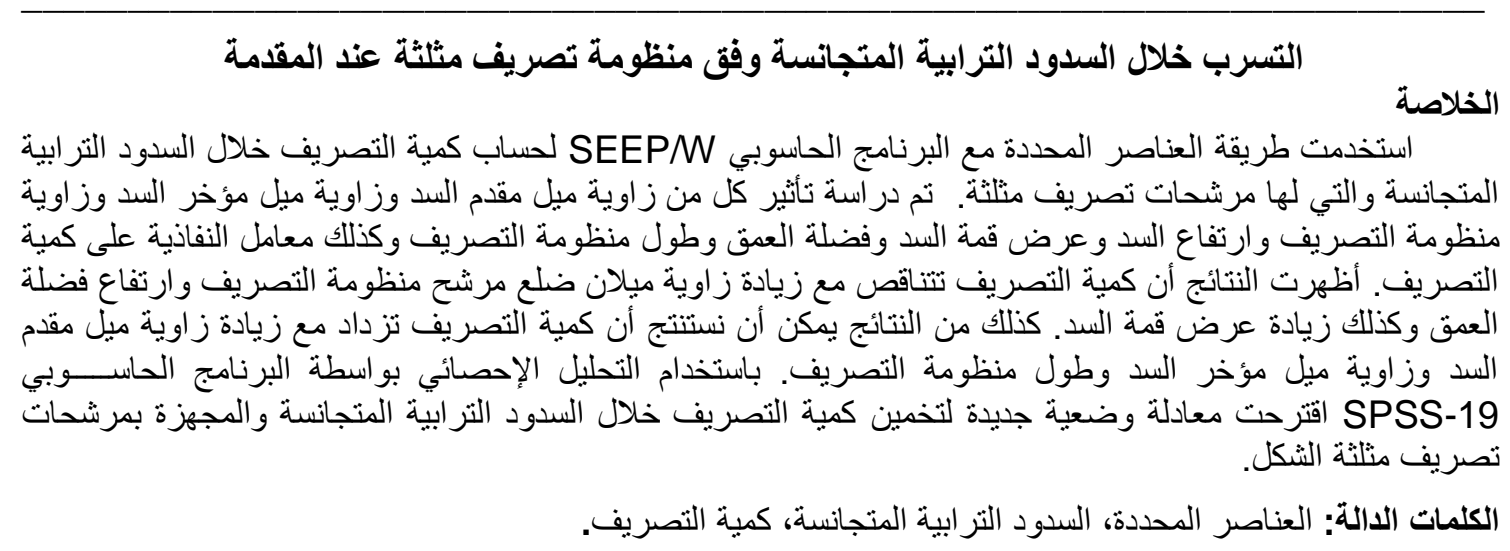

\section{Introduction}

Earth dams are generally constructed from available (earth and rock) materials. Homogeneous earth dams constructed just from one type of materials. The stability of earth dams effects greatly by the quantity of water flows through it. So that seepage control is important to prevent excess pore pressures, erosion of dams materials, piping and failure of downstream slope.

The upper line of seepage of water through earth dam is known as phreatic line. In order to protect the downstream area of dam from failure, it is necessary to keep the phreatic surface within the dam. Seepage problems and location of phreatic 
surface can be controlled by using thin layers of gravel or similar materials in the downstream section of dams. This thin layers are called drains or filters. Usually the homogeneous earth dams are built with horizontal or triangular toe filter.

The theory of flow through porous media can be used to estimate the quantity of water flow through earth dam and locate the upper flow line (phreatic line). Researchers have adopt different analytical, graphical, empirical and numerical methods to calculate quantity of seepage and phreatic line location. Based on Dupuit theory some researchers introduced different methods to calculate the quantity of seepage [1-3]. Another investigators used numerical methods such as finite difference method [4], finite element method[5-10] and boundary element method[11] to solve the problems of seepage through earth dams. Casagrande[3] developed ozenyk's solution to calculate the quantity of seepage and phreatic line location of homogeneous earth dam with triangular toe filter.

In this research, a computer program called SEEP/W was utilized to calculate the amount of flow through homogeneous earth dam with triangular filter. The effect of several parameters on the quantity of seepage were investigated. By helpful of the statistics software program called SPSS-19, a new empirical simple equation was suggested to estimate the seepage quantity through earth dams with triangular toe filter.

\section{Computer Program (SEEP/W)}

The quantity of seepage of homogeneous earth dams with triangular toe filter were investigated by a computer program SEEP/W. This program used finite element method as a tool for analysis. Real physical processes of water flowing through a porous medium can mathematically simulated by SEEP/W. Saturated and unsaturated flow problems can be solved by this program [12]. The software program SEEP/W used the following equation for formulation of flow :-

$\frac{\partial}{\partial x}\left(k_{x} \frac{\partial h}{\partial x}\right)+\frac{\partial}{\partial y}\left(k_{y} \frac{\partial h}{\partial y}\right)+Q=\frac{\partial \Theta}{\partial t} \ldots .$.

Where:

$h=$ total head

$k x=$ hydraulic conductivity in the $x$-direction $k y=$ hydraulic conductivity in the $y$-direction

$Q=$ applied boundary discharge

$\theta=$ volumetric water content

$t=$ time .

For steady-state situations, the flow entering and leaving an elemental volume is the same at all times. So that Equation (1) modified to the following form:

$\frac{\partial}{\partial x}\left(k_{x} \frac{\partial h}{\partial x}\right)+\frac{\partial}{\partial y}\left(k_{y} \frac{\partial h}{\partial y}\right)+Q=0$

However it should be noted that in this study it was assumed isotropic hydraulic conductivity:

or $k_{x}=k_{y}=k$.

The program SEEP/W employs the Green and Corey procedure (1971), for calculating the conductivity function from a soil-water characteristic function. Defining the hydraulic conductivity for negative porewater pressure regions makes it possible to analyze problems involving unsaturated flow as well as saturated flow[12]. Many investigators used SEEP/W program to study different seepage problems[13-16].

\section{Parametric Study}

Figure (1), shows the typical crosssection of homogenous earth dam with triangular toe filter that considered in this study. From Figure (1), the possible variables affecting on the quantity of seepage (q) are:-

$\alpha=$ angle of upstream of the dam.(degree)

$\beta$ =angle of downstream of the dam (degree)

$\theta=$ angle of upstream of toe filter (degree)

$\mathrm{hd}=$ heigth of the dam $(\mathrm{m})$

hw =heigth of the water in the upstream face of dam $(\mathrm{m})$

$\mathrm{Fb}=$ free board $(\mathrm{m})$

$\mathrm{Cw}=$ crest width of dam $(\mathrm{m})$

$\mathrm{L}=$ length of tringular toe filter $(\mathrm{m})$

$\mathrm{k}=$ coffecient of permeability of soil $(\mathrm{m} / \mathrm{sec})$

The quantity of seepage (q) through earth dam which calculate by toe drain can be functicuantly depend on the above influencey of prameters where:-

$q=f(\alpha, \beta, \theta, K, h d, F b, C w, L) \ldots .(4)$

The effect of these eigth varibles on the quantity of flow of homogeneous earth dams with tringular toe filter were studied in this research. 
Three values for each of the above eight varibles were taken to study thier effect on the amount of flow. So that a total numbers of running employed by SEEP/W programm were (2592).

The runs of program were applied with three values of angle of upstrem of dam (a) $\left(22^{\circ}, 20^{\circ}\right.$ and $\left.18^{\circ}\right)$, three values of angle of downstrem of dam $(\beta)\left(22^{\circ}, 24^{\circ}\right.$ and $26.5^{\circ}$ ), three values of angle of upstrem of toe filter $(\theta)\left(25^{\circ}, 50^{\circ}\right.$ and $\left.70^{\circ}\right)$, three values of earth dam hieght (hd) (16,15 and $14 \mathrm{~m})$, three values of dam crest width (Cw) ( 4, 5 and $6 \mathrm{~m})$, three values of free board (Fw) $(1,1.5$ and $2 \mathrm{~m})$, three values of length of toe filter $(L)(10,15$ and $20 \mathrm{~m})$ and three values of coffecient of permeabilty $(k)$ $(0.0001,0.00001$ and $0.000001 \mathrm{~m} / \mathrm{sec}$.).

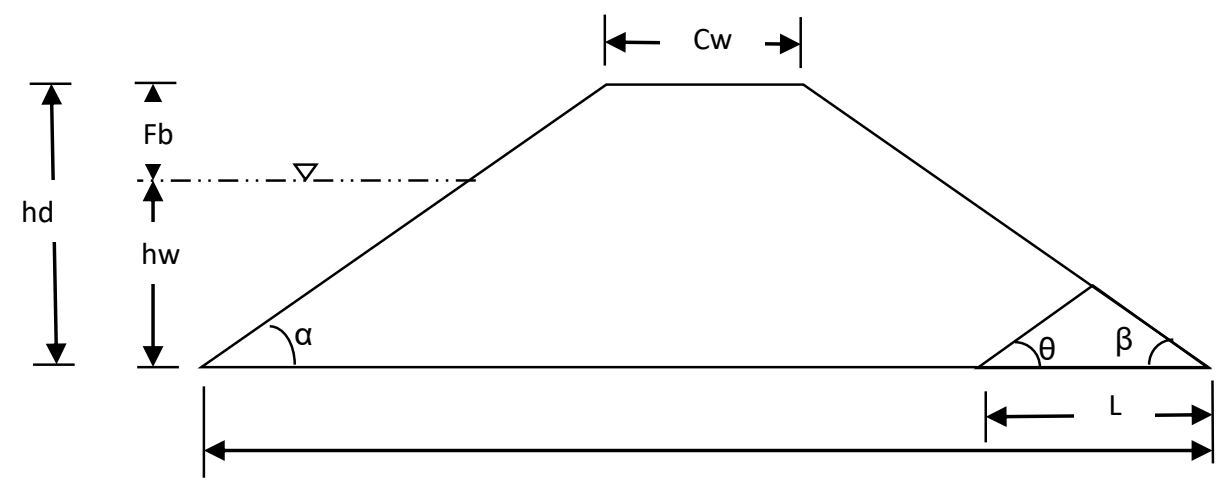

Fig. 1. Typical section of homogeneous earth dams with tringular toe filter

\section{Results and Discussion}

The quantity of flow (q) was recorded for each run in SEEP/W program. From these results, the effect of each parameters on amount of flow through homogeneous dams with triangular toe filter may be summarized as following:-

\section{Effect of Upstream Slope Angle (a)}

Figure (2), shows the relationship between the flow quantity (q) and angle of upstream slope $(\alpha)$ for different values of dam crest width ( $\mathrm{Cw}$ ) and angle of toe filter $(\theta)$. From this figure it can be appear that, if angle of dam downstream $(\beta)$, dam height (hd), free board $(\mathrm{Fb})$, length of toe filter (L) and permeability coefficient (K) are constant, the amount of seepage increases with increasing angle of upstream slope ( $\alpha$ ). So this figure shows that for the same magnitude of angle of upstream slope ( $\alpha$ ), angle of downstream slope $(\beta)$, angle of toe filter $(\theta)$, dam height (hd), free board $(\mathrm{Fb})$ and length of toe filter (L), the flow quantity (q) decreases with increasing dam crest width $(\mathrm{Cw})$. Furthermore this figure illustrate that, the seepage quantity (q) increases with decreasing angle of toe filter $(\theta)$ when all other variables remain constant.

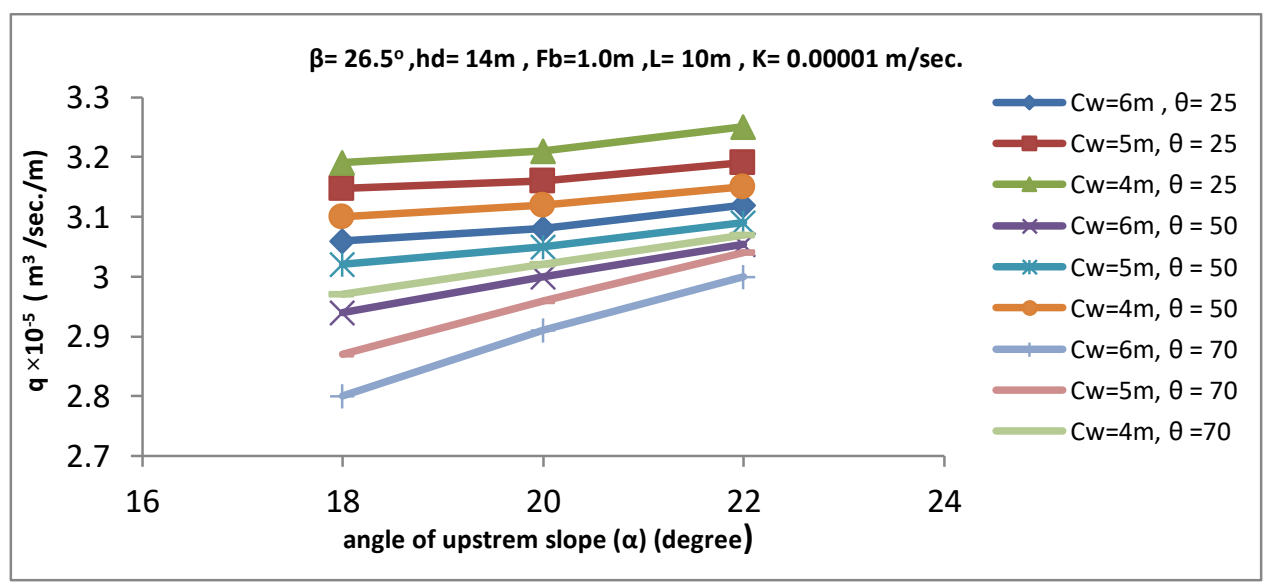

Fig. 2. Relationship between quantity of flow (q) and upstream slope angle of earth dam ( $\alpha$ ) 


\section{Effect of Downstream Slope Angle( $\beta)$}

Fig. (3) presents the relationship between the seepage quantity (q) and angle of downstream slope $(\beta)$ for different values of dam crest width (Cw) and angle of toe filter $(\theta)$. From this figure it can be shown that, if angle of upstream slope $(\alpha)$, dam height (hd), free board (Fb), length of toe filter (L) and permeability coefficient (K) are constant, the amount of flow increases with increasing angle of downstream slope $(\beta)$. Also, this figure shows that, the flow quantity $(q)$ increases with decreasing dam crest width (Cw) and decreasing angle of upstream of toe filter $(\theta)$ when all other variables remain constant.

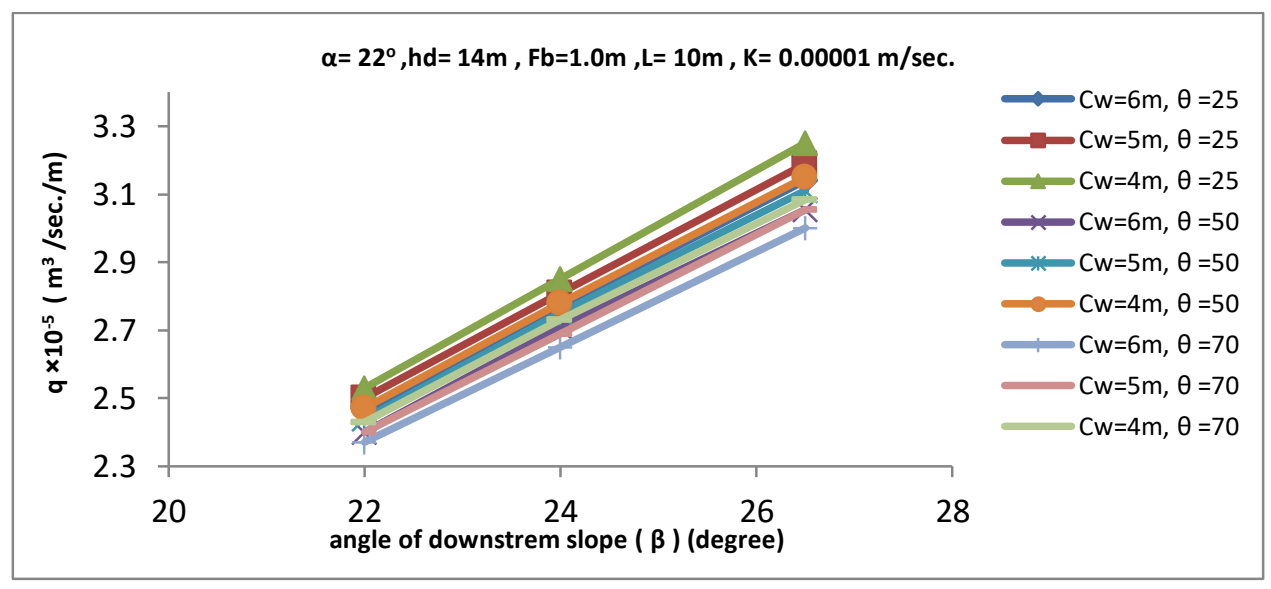

Fig. 3. Relationship between quantity of flow (q) and downstream slope angle of earth dam ( $\beta$ )

\section{Effect of Angle of Toe Filter $(\theta)$}

The relationship between quantity of seepage (q) and angle of toe filter ( $\theta$ ) for different values of dam height (hd) and free board $(\mathrm{Fb})$ is show in Figure (4). From this figure it can be seen that, the amount of flow decreases with increasing the angle of toe filter $(\theta)$ if other variables $(\alpha, \beta, L$ and $\mathrm{Cw})$ are remain constant.

\section{Effect of Crest Width of Dam (Cw)}

The relationship between seepage quantity (q) and crest width of dam (Cw) is shown in Figure (5) for different values of dam height (hd) and free board $(\mathrm{Fb})$. From this figure it can be concluded that, the quantity of seepage (q) decreases with increasing crest width of dam (Cw) if other parameters remain constant. This figure shows the same trends that shown in Figures (3) and (4).

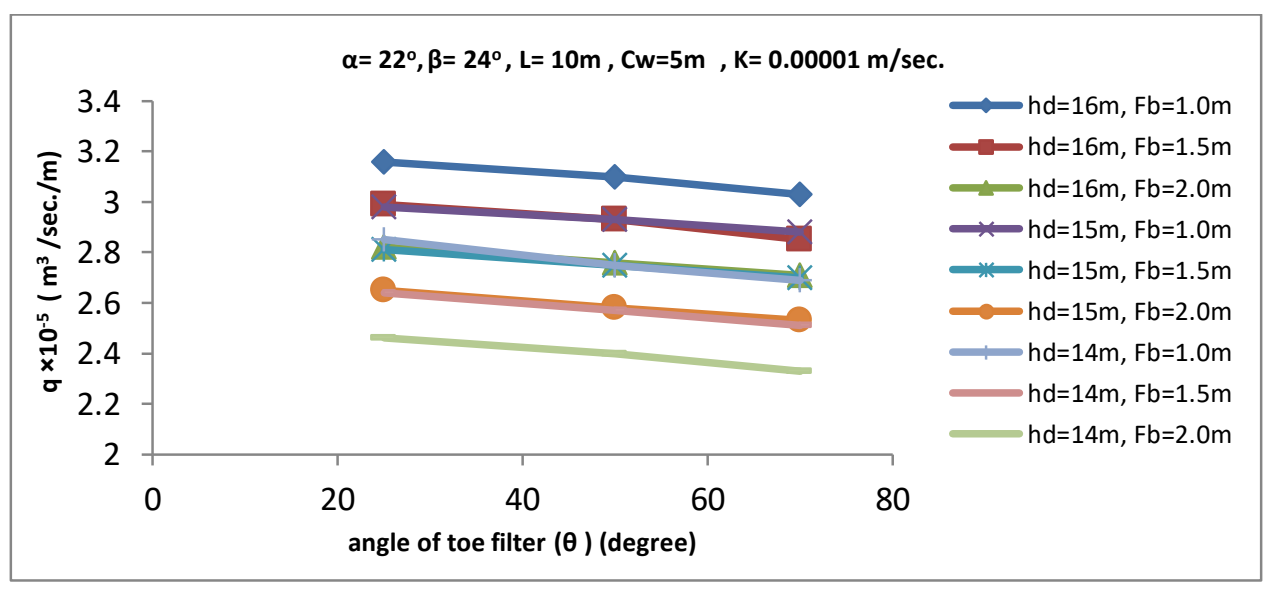

Fig. 4. Relationship between quantity of flow (q) and angle of toe filter of earth dam ( $\theta$ ) 


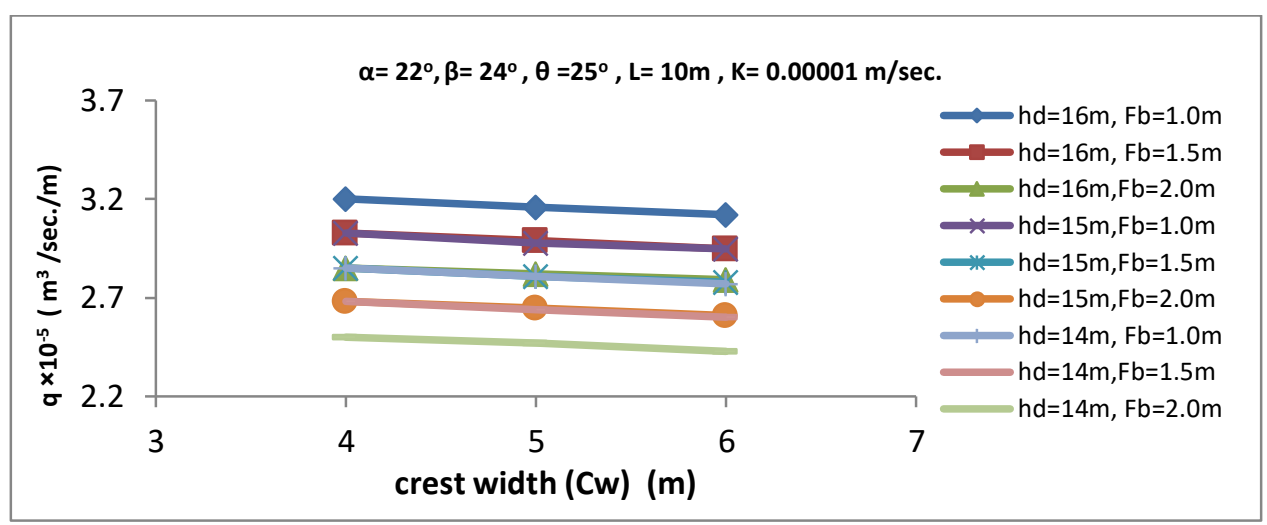

Fig. 5. Relationship between quantity of flow (q) and crest width of earth dam (Cw)

\section{Effect of the Dam Height (hd)}

Figure (6) shows the relationship between seepage quantity (q) and height of dam (hd) for different values of free board $(\mathrm{Fb})$ and angle of toe filter $(\theta)$ while other parameters ( $\alpha, \beta, L$ and $C w$ ) are constant. From this figure it can be seen that, the amount of flow (q) increases with increasing height of dam (hd). Also can be seen that, the quantity of flow decreases with increasing in the angle of toe filter $(\theta)$ as shown previously in Figure (4).

Figure (7) also shows the relationship between seepage quantity (q) and dam height (hd) but for different values of free board $(\mathrm{Fb})$ and crest width of dam $(\mathrm{Cw})$ while other parameters $(\alpha, \beta, \theta$ and $L)$ are constant.

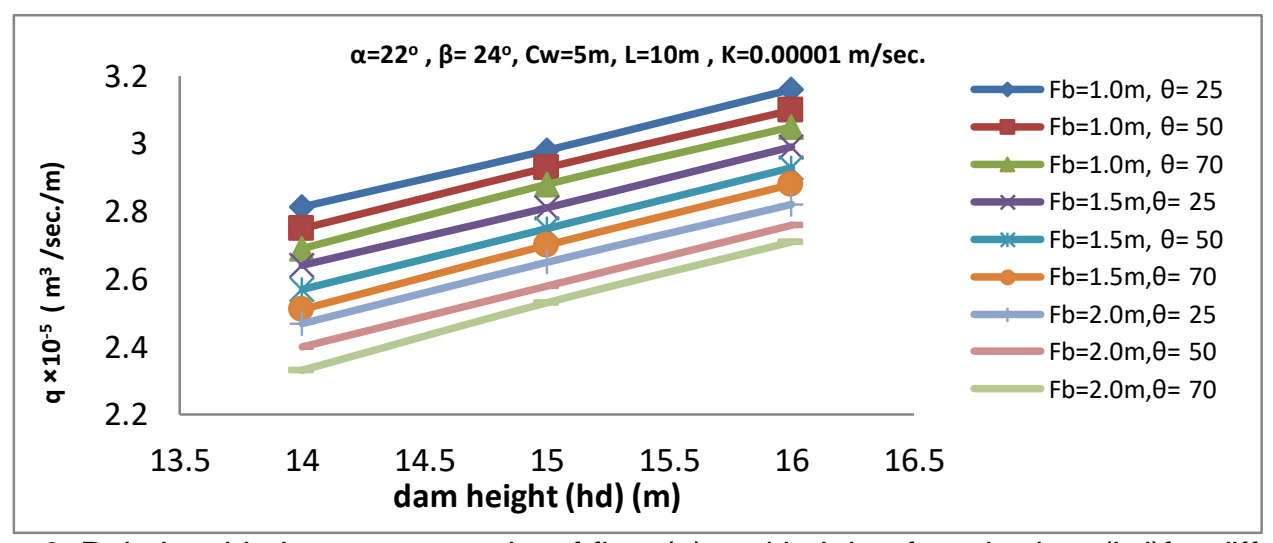

Fig. 6. Relationship between quantity of flow (q) and height of earth dam (hd)for different values for free board $(\mathrm{Fb})$ and angle of toe filter $(\theta)$

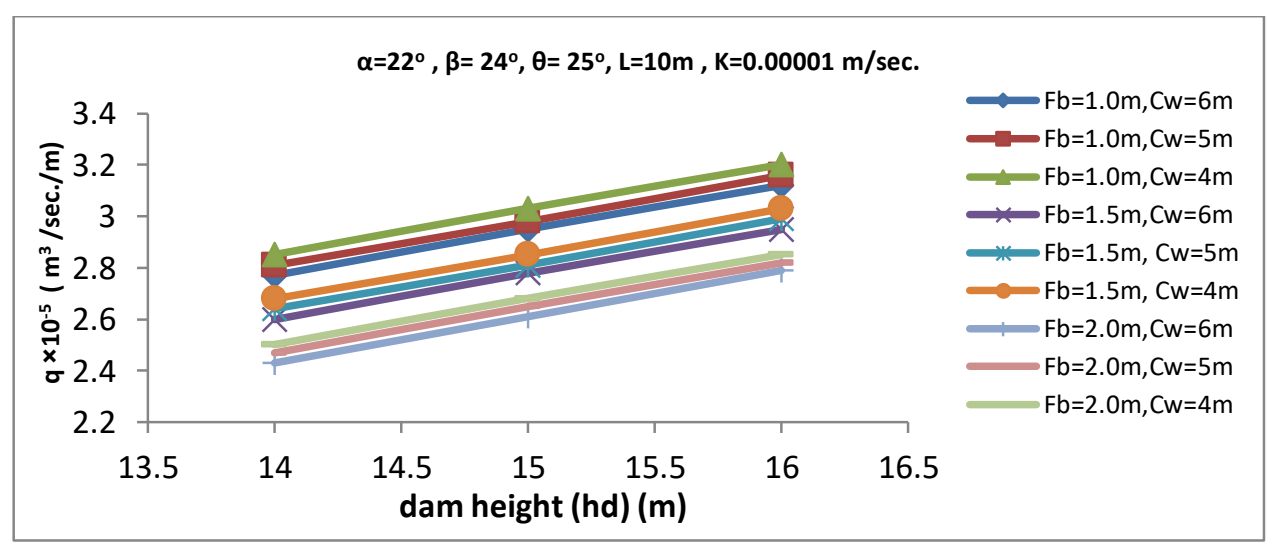

Fig. 7. Relationship between quantity of flow (q)and height of earth dam (hd) for different values for free board $(\mathrm{Fb})$ and dam crest width $(\mathrm{Cw})$ 


\section{Effect of Toe Filter Length (L)}

The relationship between the seepage quantity (q) and length of toe filter for different values of angle of toe filter is shown in Figure (8). From this figure it can be concluded that, the quantity of seepage (q) increases with increasing length of toe filter if other parameters remain constant. Also this figure shows the effect of angle of toe filter $(\theta)$ on the quantity of seepage, it can be seen that, the seepage quantity decreases with increasing angle of toe filter $(\theta)$ if other parameters remain constant.

\section{Effect of Free Board (Fb)}

The relation between seepage quantity (q) and height of free board (Fb) for different values of dam height (hd) and dam crest width (Cw) is shown in Figure (9). This figure can be show that, the quantity of seepage (q) decreases with increasing free board height $(\mathrm{Fb})$ when other parameters remain constant. This trend due to, when the free board height increasing the water depth (hw) in the upstream side of dam decreasing and lead to decreasing in the quantity of seepage.

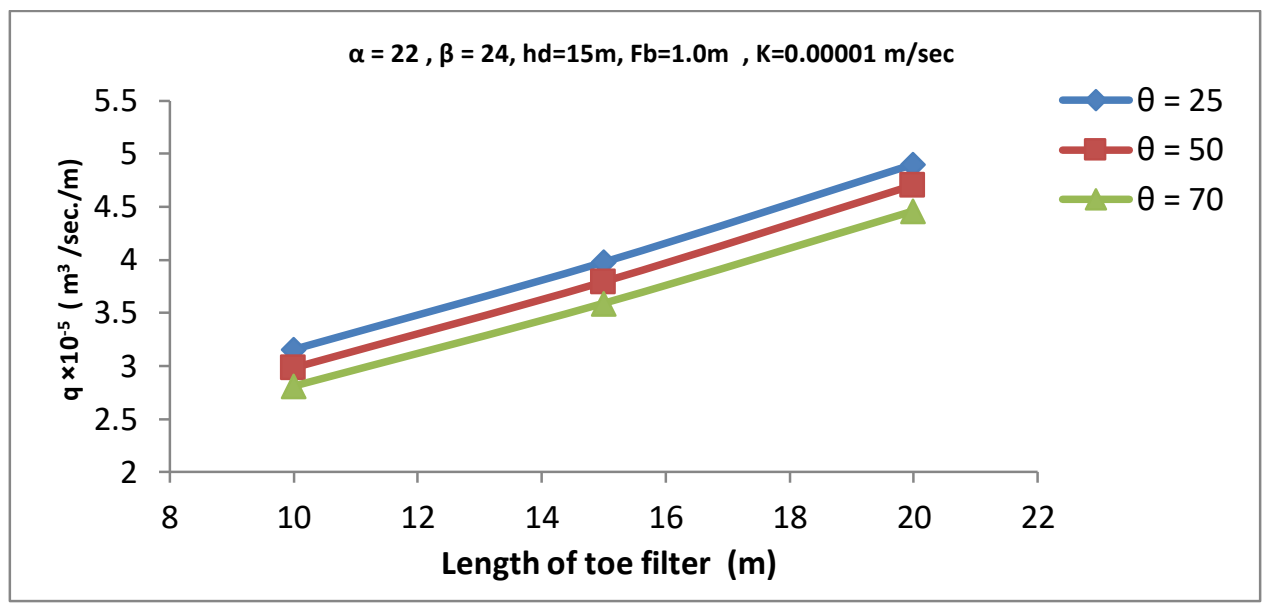

Fig. 8. Relationship between quantity of flow (q) and length of toe filter ( $L$ ) of earth dam

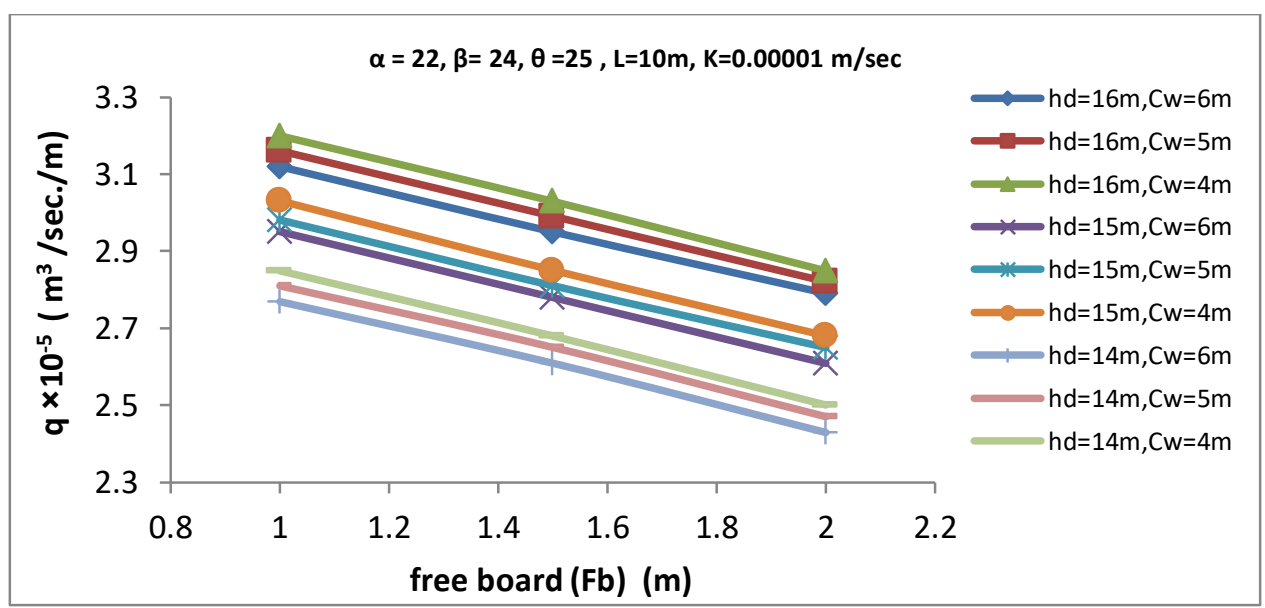

Fig. 9. Relationship between quantity of flow (q) and height of free board (Fb) of earth dam

\section{Statistical Analysis}

The results of the SEEPM models were statistically analyzed by SSPS-19 computer program to develop a new proposal empirical equation for estimating quantity of seepage through homogeneous earth dams with triangular toe filter. Two third of the above results were used in the SSPS-19 program. The new proposal equation is developed as shown below with coefficient of determination $R^{2}$ equal to 0.94 :- 
$q=$

$\frac{0.4374 K \cdot L^{0.599} \cdot \tan \alpha^{0.306} \cdot \tan \beta^{0.846} \cdot h d^{0.593}}{C w^{0.066} \cdot F b^{0.197} \cdot \tan \theta^{0.021}}$

Figure (10) shows the relationship between one third residual results of the seepage quantity were computed by SEEPM software and that which determined by Equation (5) using the same geometry dimensions and boundary condition. From this figure it can be noted a good conformities between the results of the new proposal equation and SEEP/W software.

For more examination of the accuracy and validity of the new proposal equation, it was carried out on a number of homogenous earth dams having dimensions outside the range of the dimensions that were taken in the development of the new empirical equation. The results of flow quantity calculated by this equation show a very small difference when comparing with the results computed by SEEPM software, as shown in Table (1). The results show that the new empirical equation has good confidence when using to calculate the amount of flow through homogeneous earth dam with triangular filter.

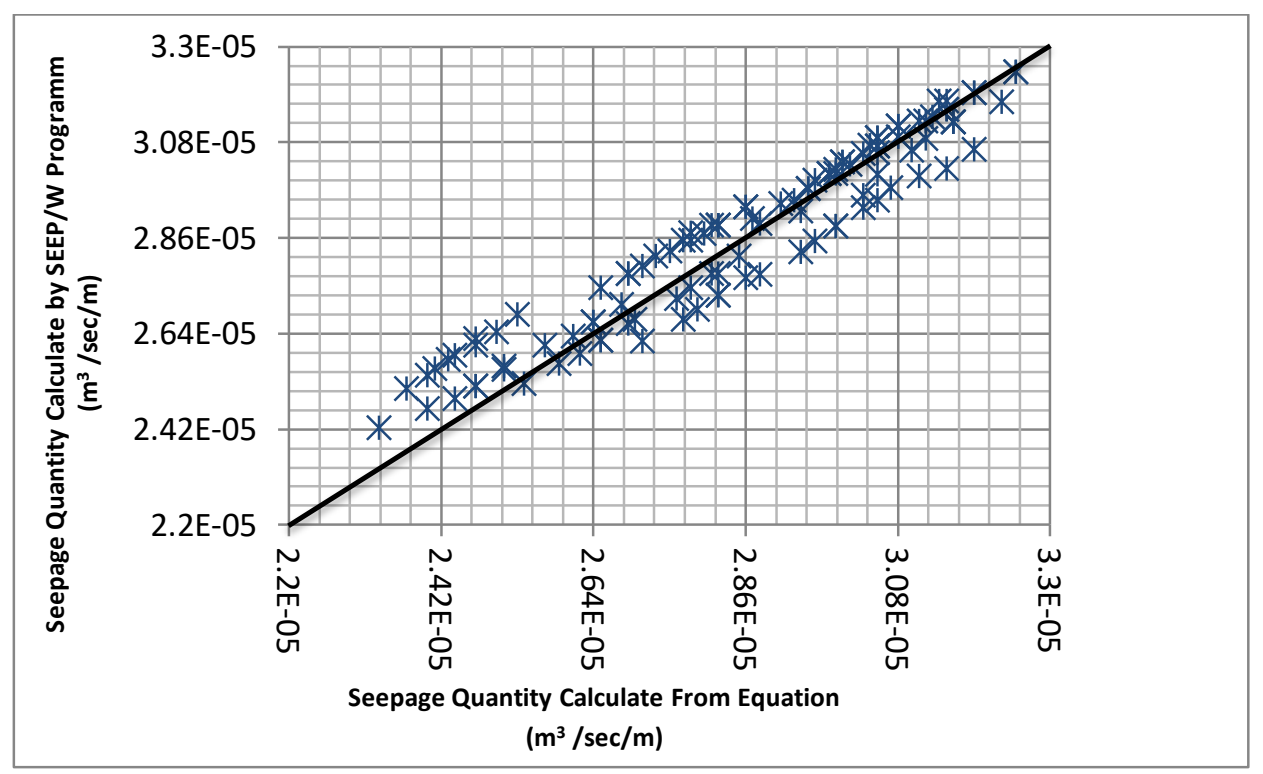

Fig. 10. Relationship between the flow quantity calculated by SEEP/W program and calculated from empirical equation

Table 1. Flow quantity calculated by SEEP/W Program and empirical equation

\begin{tabular}{|c|c|c|c|c|c|c|c|c|c|c|}
\hline \multirow{2}{*}{$\begin{array}{c}\alpha \\
(\text { degree })\end{array}$} & \multirow{2}{*}{$\begin{array}{c}\beta \\
\text { (degree) }\end{array}$} & \multirow{2}{*}{$\begin{array}{c}\theta \\
(\text { degree })\end{array}$} & \multirow{2}{*}{$\begin{array}{l}\text { hd } \\
(\mathrm{m})\end{array}$} & \multirow{2}{*}{$\begin{array}{l}\mathrm{Fb} \\
(\mathrm{m})\end{array}$} & \multirow{2}{*}{$\begin{array}{l}\mathrm{Cw} \\
(\mathrm{m})\end{array}$} & \multirow[t]{2}{*}{$\mathrm{L}(\mathrm{m})$} & \multirow{2}{*}{$\begin{array}{c}\mathrm{K} \\
\left(\mathrm{m}^{3} / \mathrm{sec} / \mathrm{m}\right. \\
)\end{array}$} & \multicolumn{2}{|c|}{$\begin{array}{l}\text { Seepage Quantity } \\
\left(\mathrm{m}^{3} / \mathrm{sec} / \mathrm{m}\right)\end{array}$} & \multirow{2}{*}{$\begin{array}{c}\text { Difference } \\
\%\end{array}$} \\
\hline & & & & & & & & SEEP/W & Equation & \\
\hline 16 & 22 & 30 & 10 & 1.5 & 3 & 13 & $1 \times 10^{-5}$ & $2.09 \times 10^{-5}$ & $2.17 \times 10^{-5}$ & +4 \\
\hline 16 & 22 & 45 & 13 & 2 & 5 & 17 & $1 \times 10^{-5}$ & $2.74 \times 10^{-5}$ & $2.84 \times 10^{-5}$ & +3.77 \\
\hline 16 & 22 & 60 & 17 & 2.5 & 3.5 & 22 & $1 \times 10^{-5}$ & $3.45 \times 10^{-5}$ & $3.56 \times 10^{-5}$ & +3.33 \\
\hline 20 & 23 & 30 & 9 & 1 & 2.5 & 12 & $1 \times 10^{-5}$ & $2.46 \times 10^{-5}$ & $2.41 \times 10^{-5}$ & -1.89 \\
\hline 20 & 24 & 45 & 12 & 1.5 & 4 & 16 & $1 \times 10^{-5}$ & $3.21 \times 10^{-5}$ & $3.12 \times 10^{-5}$ & -2.6 \\
\hline 20 & 21 & 60 & 17 & 2 & 6 & 23 & $1 \times 10^{-5}$ & $3.75 \times 10^{-5}$ & $3.83 \times 10^{-5}$ & +2.17 \\
\hline 21 & 26.5 & 30 & 8 & 1 & 2.5 & 10 & $1 \times 10^{-5}$ & $2.42 \times 10^{-5}$ & $2.35 \times 10^{-5}$ & -2.48 \\
\hline 21 & 25.5 & 45 & 12 & 1.5 & 3 & 12 & $1 \times 10^{-5}$ & $2.78 \times 10^{-5}$ & $2.89 \times 10^{-5}$ & +4.09 \\
\hline 21 & 24 & 60 & 19 & 2 & 4 & 16 & $1 \times 10^{-5}$ & $3.78 \times 10^{-5}$ & $3.89 \times 10^{-5}$ & +3.16 \\
\hline
\end{tabular}




\section{Conclusion}

Depending on the results and analysis of this study, the following main conclusions can be summarized as :-

1- The amount of flow through homogeneous earth dam increased with increasing the angle of upstream slope and angle of downstream slope.

2- The effect of changing angle of downstream slope on the quantity of seepage is more than that changing in the angle of upstream slope.

3- The seepage quantity decreased with increasing the angle of toe filter and width of dam crest

4- The quantity of seepage increased with increasing the length of triangular toe filter base.

5- Based on statistical analysis a new empirical equation was suggested to estimate the amount of flow through homogeneous earth dam with triangular toe filter.

\section{References}

1. Pavlovasky NN. Seepage through earth dams. Inst. Leningrad: Gidrotehniki I Melioratsii; 1956.

2. Mishra CG, Parida BP. Earth dam toe drain on an impervious base. International Journal of Geomechanics 2006;6(6):1.

3. Harr ME. Ground water and seepage. New York: McGraw-Hill Book Company; 1962.

4. Kermani FE, Barani GA. Seepage analysis through earth dam based on finite difference method. Journal of Basic and Applied Scientific Research 2012;2(11):11621-11625.

5. Freeze RA. Influence of the unsaturated flow domain on seepage through earth dams. Water Resource Research 1971;7(4):929-941.

6. Dunbar SW, Sheahan TC. Seepage control remediation at hodges village dam. Journal of Geotechnical and
Geoenvironmental Engineering, ASCE 1999;125(3):198-206.

7. Kasim F. Numerical parametric simulations for seepage flow behavior through earth fill dam. Journal Keiuruteraan AWAM 2002;14(1).

8. Nasim S. Seepage analysis of earth dams by finite elements. M.Sc. Thesis. Kufa, Iraq: University of Kufa; 2007.

9. Kazemzadeh MJ. Unconfined seepage analysis in earth dams using smoothed fixed grid finite element method. International Journal for Numerical and Method in Geomechanics 2012;36(6):780- 797.

10. Olande KA, Agbede OA. A study of seepage through oba dam using finite element method. Civil and Environmental Research 2013;3(3):5360.

11. Abdel-Gawad, Shamaa. Seepage through earth dams with horizontal filters and founded on impervious foundation (numerical analysis with boundary element method). Alexandria Engineering Journal 2004;43(6).

12. An Engineering Methodology, "Seepage Modeling with SEEP/W", GEO-SLOPE International Ltd., 2007.

13. Singh AK. Analysis of flow in a horizontal toe filter. International Association for Computer Methods and Advances in Geomechanics (IACMAG) 2008:2449-2455.

14. Khattab, SAA. Stability analysis of Mousl dam under saturated and unsaturated soil conditions. Al-Rafidain Engineering Journal 2009;18(1).

15. Zomorodian ASM, Abodollahzadeh, MS. Effect of horizontal drains on upstream slope stability during rapid drawdown condition. International Journal of Geology 2010;4(4):85-90.

16. Arshed I, Babar MM. Compression of SEEPM simulation with field observation for seepage analysis through earth dam. International Journal of Research 2014;7(1). 